\title{
Determination of the contact angles of kaolin intercalates of oleochemicals derived from rubber seed (Heveabrasiliensis) and tea seed (Cameliasinensis) oils by the capillary rise method
}

\author{
Chinedum Ogonna Mgbemena ${ }^{1, ~}$, Chika Edith Mgbemena $^{2}$, Rugmini Sukumar $^{3}$, \\ A. R. R. Menon ${ }^{3}$ \\ ${ }^{1}$ National Engineering Design Development Institute, Nnewi, Nigeria \\ ${ }^{2}$ Department of Industrial/Production Engineering, NnamdiAzikiwe University, Awka, Nigeria \\ ${ }^{3}$ National Institute for Interdisciplinary Science and Technology, Thiruvananthapuram, India
}

\section{Email address:}

mgbemenachinedum@neddinaseni.org(C.O.Mgbemena),ce.mgbemena@unizik.edu.ng(C.E. Mgbemena), rugmini_s@rediffmail.com(R. Sukumar),drarrmenon@gmail.com(A. R. R. Menon)

\section{To cite this article:}

Chinedum Ogonna Mgbemena, Chika Edith Mgbemena, RugminiSukumar, A. R. R. Menon. Determination of the Contact Angles of Kaolin Intercalates of Oleochemicals Derived from Rubber Seed (HeveaBrasiliensis) and Tea Seed (CameliaSinensis) Oils by the Capillary Rise Method. International Journal of Materials Science and Applications. Vol. 2, No. 3, 2013, pp. 99-103. doi: $10.11648 /$ j.ijmsa.20130203.15

\begin{abstract}
Pristine kaolin was organically modified by employing derivatives of oleochemicals namely rubber seed oil (SRSO) and tea seed oil (STSO). Intercalation was attained by the entrance of hydrazine hydrate as co-intercalate. Characterization of the pristine kaolin and modified kaolin was done using powder X-ray diffraction which revealed increase in the interlayer basal spacing d-001 for the SRSO-modified and STSO-modified kaolins, confirming intercalation process. The FTIR studies further revealed that the fatty acid salts of rubber seed oil and tea seed oil were effectively intercalatedin the kaolinite layers as per the bands at $1564 \mathrm{~cm}^{-1}$ and $1553 \mathrm{~cm}^{-1}$ for SRSO-modified and STSO-modified kaolins respectively. The contact angle measurement using capillary rise method was performed to confirm that the pristine kaolin with initial contact angle value of $\sim 45^{\circ}$ was effectively modified and 'wetted' from hydrophilic state to hydrophobic state of $\sim 90^{\circ}$ for the SRSO-modified and STSO-modified kaolin.The determination of the contact angles of the kaolin was performed to confirm intercalation of the modified kaolin with the oleochemical derivatives.
\end{abstract}

Keywords: Kaolin, Contact Angles, Capillary Rise, Rubber Seed Oil, Tea Seed Oil, Intercalation

\section{Introduction}

The capillary rise method is a practical approach for the determination of contact angle which is employed to a great extent in characterizing porous materials by measuring the rate of liquid permeation within the porous structures of the material (Xue et al., 2006). Fluid interactions and dynamics in porous structures are multidisciplinary and are also subject of interest to researchers (Soriano et al., 2005; Xue et al., 2006).The characterization of the surface properties, especially the contact angle measurements is the key to understanding the mechanism of surface-based phenomena.

Kaolin which consists mainly of the mineral Kaolinite with empirical formula of $\mathrm{Al}_{2} \mathrm{Si}_{2} \mathrm{O}_{5}(\mathrm{OH})_{4}$ and theoretical chemical composition as: $\mathrm{SiO}_{2} 46.54 \% ; \mathrm{Al}_{2} \mathrm{O}_{3} 39.50 \%$; and $\mathrm{H}_{2} \mathrm{O} 13.96 \%$ is classified as a mesoporous material and is used in various applications, including paper coatings, ceramics manufacture, paint, plastics, cosmetics, etc.(Mgbemena et al., 2013; Krishnan et al., 2012; Guessoumet al., 2012; Preetha and Rani, 2012; Songfang et al., 2011; Ma and Bruckard, 2010; Murray,2007; Ciullo, 1996).

Contact angle measurements are very easy to perform on smooth flat surfaces. There are many established techniques for measuring the contact angles of liquids on flat surfaces (Neumann and Good, 1979). However, in industrial applications, materials are used in powdered form which makes it difficult to obtain the value of contact angle for 
these materials. It is therefore impractical to use the conventional contact angle measurement techniques for the characterization of fine powders such as kaolin.

There are many simple and fast methods of determination of contact angles on flat surfaces and they include: sessile drop (captive bubble), inclined plate, and Wilhelmy's plate methods.Among the techniques developed for contact angle measurements on powders is the capillary rise technique, also known as Washburn method and the thin layer wicking technique. Other proven methods are the compressed disc, film flotation and recently the atomic force microscopy. The Washburn method or capillary rise method is the most commonly used technique for powders (Hołownia et al., 2008; Xue et al., 2006; Xu and Masliyah, 2002).

Washburn (1921)and Lucas (1918)explained clearly the dynamics of capillary rises by employing the Poiseuille equation with driving force for the rise described by the Laplace equation for the pressure difference across the incursive liquid meniscus.

In this study, kaolin intercalates of oleochemicals derived from Rubber Seed (Heveabrasiliensis) and Tea Seed (Cameliasinensis) oils were subjected to contact angle measurements via the capillary rise method to further verify the extent of wettability, intercalation and the extent of modification of the kaolin with the oleochemicals. The kaolin intercalates and pristine kaolin were initially subjected to powder X-ray diffraction (XRD) and Fourier transform infrared spectroscopy(FTIR) to determine the extent of interactions morphologically with the oleochemicals before experimental measurements were performed to determine the contact angles via the capillary rise method.

\section{Experimental}

\subsection{Materials}

Kaolin (grade BCK) used in this study was obtained from $\mathrm{M} / \mathrm{s}$. English Indian Clays Ltd, Veli, Thiruvananthapuram, Kerala, India. The Physicochemical Characteristics of kaolin are given in Table 1. The Rubber Seed Oil (RSO) and Tea seed Oil (TSO) were obtained from National Institute for Interdisciplinary Science and Technology (NIIST-CSIR), Thiruvananthapuram, Kerala, India; Laboratory grades of sodium hydroxide (MERCK) and hydrazine hydrate (Finnar) were obtained from local suppliers.

\subsection{RSO-Kaolin and TSO-Kaolin Treatments}

Following a similar procedure reported earlier by Rugmini and Menon (2008) and Mgbemena et al. (2013) respectively, the sodium salt of rubber seed oil (SRSO) was stoichiometrically prepared by mixing RSO with $20 \% \mathrm{NaOH}$ solution at a ratio of $1: 3$ in an ice bath with continuous stirring for $12 \mathrm{~h}$. The resulting mixture was kept for 1 day to cure. The final $\mathrm{pH}$ of the resulting solution was adjusted to 9 .
The SRSO was washed with water to remove excess of $\mathrm{NaOH}$, dried in a hot air oven and the dried product was powdered.This was followed by slowly adding kaolin and SRSO at a ratio of 4.9:1 with $70 \mathrm{~mL}$ hydrazine hydratewith vigorous stirring at $20^{\circ} \mathrm{C}$. The mixture was homogenized using an Art-MICCRA D-8 (Germany) homogenizer, and the sample was dried in a freeze drier.

The same procedure was repeated for sodium salt of tea seed oil (STSO) by reacting $28 \mathrm{~mL}$ of TSO with $27 \mathrm{~mL}$ of $20 \%$ $\mathrm{NaOH}$ solution in an ice bath with constant stirring for $12 \mathrm{~h}$ and kept for 1 day to allow for curing to take place. The $\mathrm{pH}$ of the resulting solution was adjusted to 9. STSO was washed with water to remove excess base; dried in a hot air oven to remove residual moisture and powdered. Then, kaolin was slowly added to STSO at a ratio of 4.9:1 and 70 $\mathrm{ml}$ hydrazine hydrate with vigorous stirring at $20^{\circ} \mathrm{C}$. The mixture was homogenized using an Art-MICCRA D-8 (Germany) homogenizer, and the sample was dried in afreeze drier.

Table 1. Physicochemical characteristics of the kaolin

\begin{tabular}{|c|c|}
\hline Properties & Value (\%) \\
\hline \multicolumn{2}{|l|}{ 1. Chemical Assay } \\
\hline $\mathrm{SiO}_{2}$ & 45 \\
\hline $\mathrm{Al}_{2} \mathrm{O}_{3}$ & 38 \\
\hline $\mathrm{Fe}_{2} \mathrm{O}_{3}$ (max.) & 0.5 \\
\hline $\mathrm{TiO}_{2}$ & 0.55 \\
\hline $\mathrm{CaO}(\max )$. & 0.06 \\
\hline $\mathrm{MgO}(\max )$. & 0.07 \\
\hline $\mathrm{Na}_{2} \mathrm{O}$ (max.) & 0.25 \\
\hline $\mathrm{K}_{2} \mathrm{O}$ (max.) & 0.1 \\
\hline \multicolumn{2}{|l|}{$\begin{array}{l}\text { Loss on ignition } \\
\text { at } 1025^{\circ} \mathrm{C} \pm 1{ }^{\circ} \mathrm{C}\end{array}$} \\
\hline 2. Density $(\mathrm{g} / \mathrm{cc})$ & 14.5 \\
\hline 3. Particle Size Distribution & 2.60 \\
\hline$<10 \mu \mathrm{m}$ & 97.21 \\
\hline$<5 \mu m$ & 92.40 \\
\hline$<2 \mu m$ & 62.60 \\
\hline 4. Cation Exchange Capacity & 2.90 \\
\hline (mequiv $\mathrm{NH}_{3} / 100 \mathrm{~g}$ ) & 14.30 \\
\hline 5.Surface Area $\left(\mathrm{m}^{2} / \mathrm{g}\right)$ & 4.50 \\
\hline 6.pH ( $5 \%$ solution $)$ & \\
\hline
\end{tabular}

\subsection{Characterization of the Pristine and Modified Kaolin}

\subsubsection{Powder X-ray Diffraction}

The Powder X-ray diffraction of the samples was executed on a Philips-1710 X-Ray diffractometer using monochromatic Ni-filtered $\mathrm{Cu} \mathrm{K} \alpha$ radiation $1.5418 \AA$ (Angstrom) at $40 \mathrm{kV}$ and $20 \mathrm{~mA}$. The pristine and modified kaolin were first ground into a fine powder prior to XRD measurements, using an agate mortar and pestle with sufficient pressure so as to make a fine powder. The powder samples were pressed in a glass sample holder and scanning was performed in a range of $2 \theta=5-55^{\circ}$ with a speed of $2 \% \mathrm{~min}$ and step size of $0.05^{\circ}$. All recordings were taken at room temperature. Three scans were performed for each sample and the average values were reported. The $d$-spacing was calculated using Bragg's equation:

$$
\mathrm{n} \lambda=2 \mathrm{~d} \operatorname{Sin} \theta
$$


Where $\lambda$ is the wavelength of monochromatic X-ray source measured in Angstrom $(\AA)$, ' $d$ ' is the inter-planar spacing generating the diffraction, measured in $\AA, \theta$ is the diffraction angle at which X-ray falls on the sample, and $n$ is the order of reflection.

\subsubsection{Fourier Transform Infrared Spectroscopy (FTIR)}

The FTIR spectra of the pristine and modified kaolins were obtained using MAGNA 560 NICOLET Fourier Transform Infrared spectrometer. Wave-numbers from 3800 $\mathrm{cm}^{-1}$ to $600 \mathrm{~cm}^{-1}$ were measured.

\subsection{Capillary Rise Contact Angle Measurement}

\subsubsection{Theory}

In a conventional laboratory capillary rise experiment set up, a capillary tube is closed by a filter at the tube bottom and filled with sample of powder particles to be examined. The bottom of the capillary tube is then brought into contact with the liquid. The liquid rises within the tube due to some capillary effect between the tube opening and the powder particles. The contact angle is calculated from the distance moved in the capillary and the time taken to move. The Lucas-Washburn equation for the permeation of liquid in a horizontal cylindrical capillary is given as:

$$
H^{2}=\frac{r \gamma_{L V} \operatorname{Cos} \theta}{2 \eta} t
$$

Where

$\mathrm{H}=$ distance penetrated by the liquid

$\gamma_{L V}=$ the surface tension of the liquid

$\eta=$ the viscosity of the liquid

$\mathrm{r}=$ the capillary radius

$\theta=$ the contact angle between the liquid and the capillarysurface.

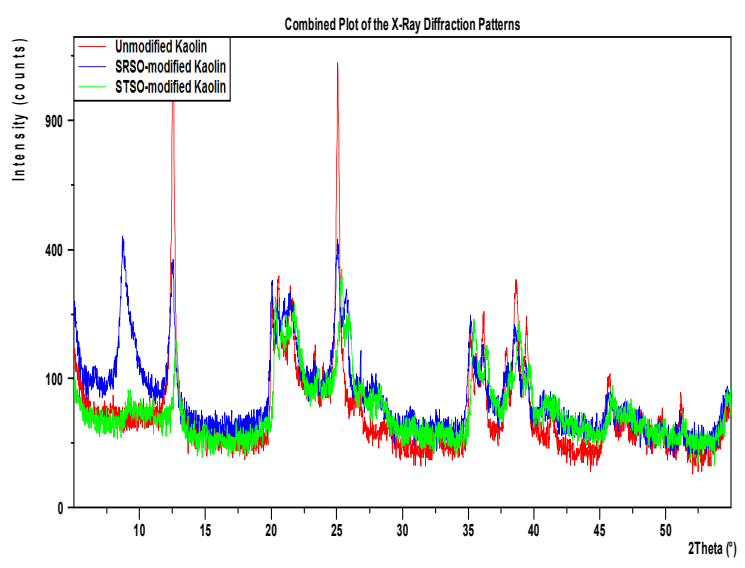

Figure 1. X-Ray Diffraction Pattern for the kaolin

\section{Results}

\subsection{Powder X-ray Diffraction}

The XRD patterns of kaolin before and after modification with hydrazine hydrate and fatty acid salts of RSO and TSO are shown in fig 1 . It was revealed from the XRD test that the pristine Kaolin gave a diffraction peak at $2 \theta=12.54^{\circ}$ which is assigned to the interlayer basal spacing $\mathrm{d}_{001}$ of 7.10 $\AA$. The SRSO-modified Kaolin, gave a diffraction peak at $2 \theta$ $=6.60^{\circ}$ with interlayer basal spacing $\mathrm{d}_{001}$ of $13.40 \AA$. In the STSO-modified Kaolin, a much lower interlayer basal spacing $\mathrm{d}_{001}$ of $9.70 \AA$ at angle $2 \theta=9.13^{\circ}$ was obtained. The value obtained for STSO-modified kaolin in this work was much lower compared to the value of $14.3 \AA$ obtained by (Yahaya et al., 2010). The value of $13.40 \AA$ recorded for SRSO-modified kaolin was low compared to the value of 14 $\AA$ obtained from an earlier study by Sukumar and Menon (2008).

\subsection{FTIR Studies}

The FTIR spectra of pristine kaolin and modified kaolin are depicted in fig 2. The pristine and modified kaolin spectra show a band at $3620 \mathrm{~cm}^{-1}$ and $3691 \mathrm{~cm}^{-1}$ which are characteristics of inner hydroxyls and vibrations of outer surface hydroxyls respectively (Dai and Huang, 1999; Cheng et al., 2012). The band at $3654 \mathrm{~cm}^{-1}$ in all the samples is due to the inner surface hydroxyl lying close to the sheet. In the modified samples, there are occurrences of bands between $2850 \mathrm{~cm}^{-1}$ and $2920 \mathrm{~cm}^{-1}$ showing that there is an intercalation of SRSO and STSO on kaolin surfaces (Bellotto et al., 1995; Gualtieri et al., 1995).

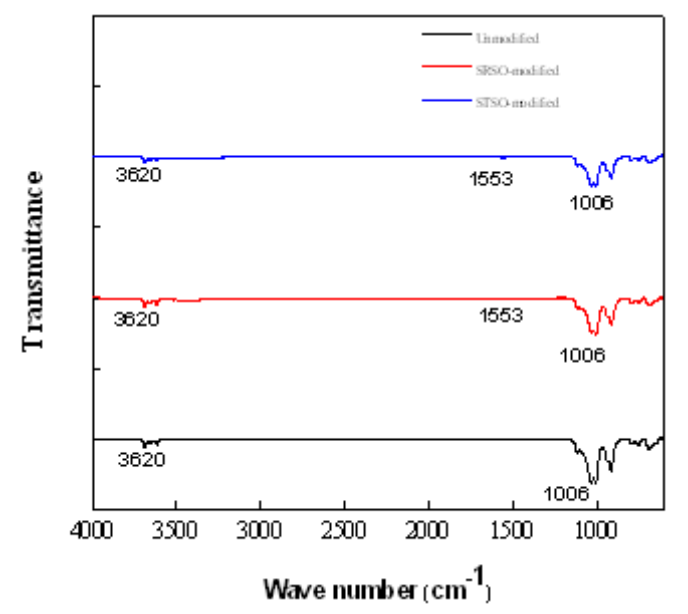

Figure 2. FTIR Spectra for Pristine, SRSO and STSO modified kaolin

\subsection{Contact Angle Measurements}

De-ionized water with kinematic viscosity of $\sim 50 \mathrm{~mm}^{2} / \mathrm{s}$ was chosen as the preferred liquid in capillary for this study. Figures 3-6 show the experimental plot of the spontaneous capillary rise and contact angles for the SRSO-modified and STSO-modified kaolin, respectively while Figures 7 and 8 show the results for the pristine kaolin. The process of capillary rise behavior obeys the Lucas-Washburn equation (Eq.2).

The contact angle calculated in this work is an advancing contact angle, $\theta_{\mathrm{A}}$. From the contact angle measurements performed for the pristine kaolin, it was found that the contact angle obtained was between $44^{\circ}-45^{\circ}$ which is an indication of hydrophilicity while the values obtained for 
SRSO-modified kaolin and STSO-modified kaolin were $89^{\circ}-89.92^{\circ}$ and $87.70^{\circ}-89.92^{\circ}$ respectively, which is an indication of hydrophobicity. The results obtained indicate that the pristine kaolin was modified from hydrophilic to hydrophobic.

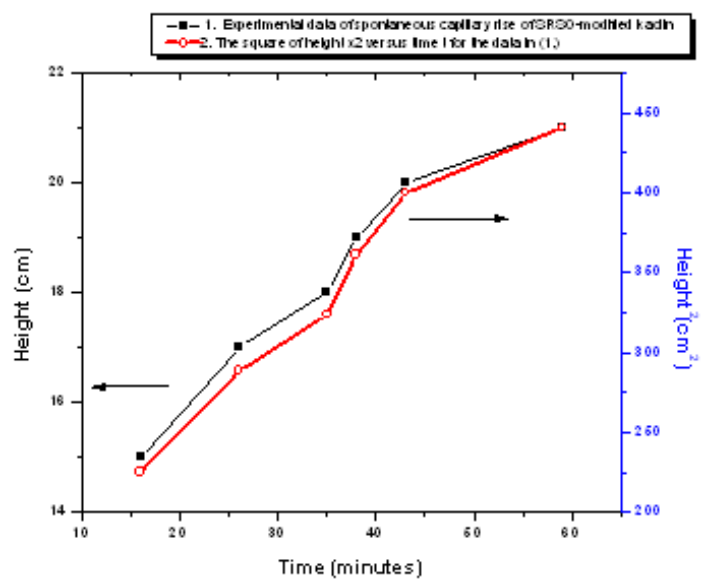

Figure 3. (a) Experimental data of spontaneous capillary rise of SRSO Modified kaolin. (b) The square of height $H^{2}$ versus time t for the data in (a).

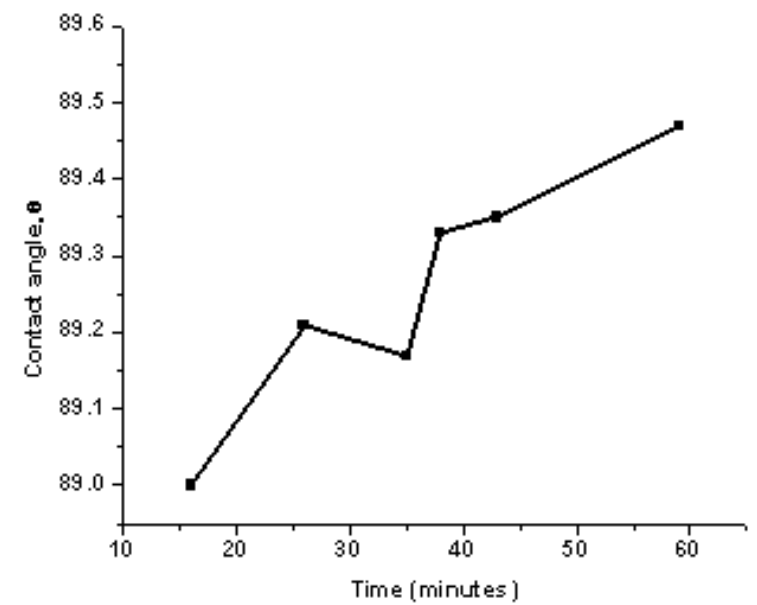

Figure 4. The Contact angle deduced for SRSO modified kaolin from the experimental data according to Equation 2.

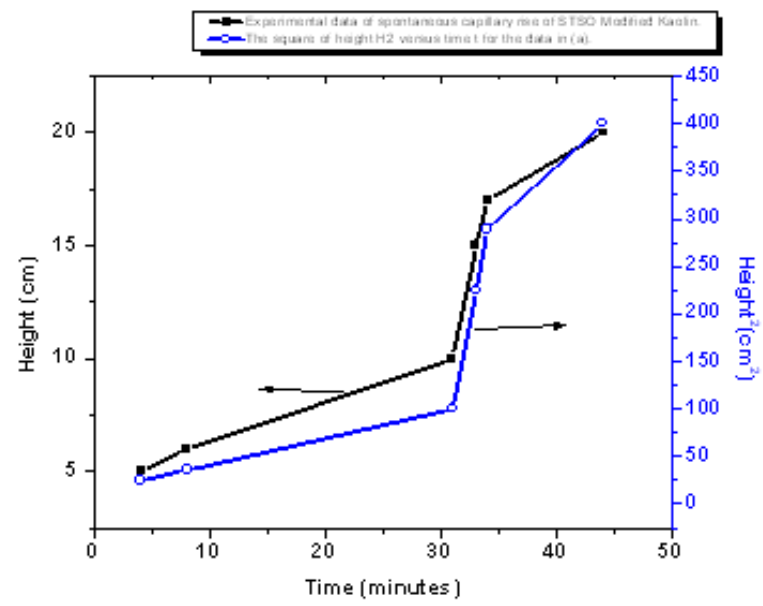

Figure 5. (a) Experimental data of spontaneous capillary rise of STSO Modified kaolin.(b) The square of height $H^{2}$ versus time t for the data in (a).

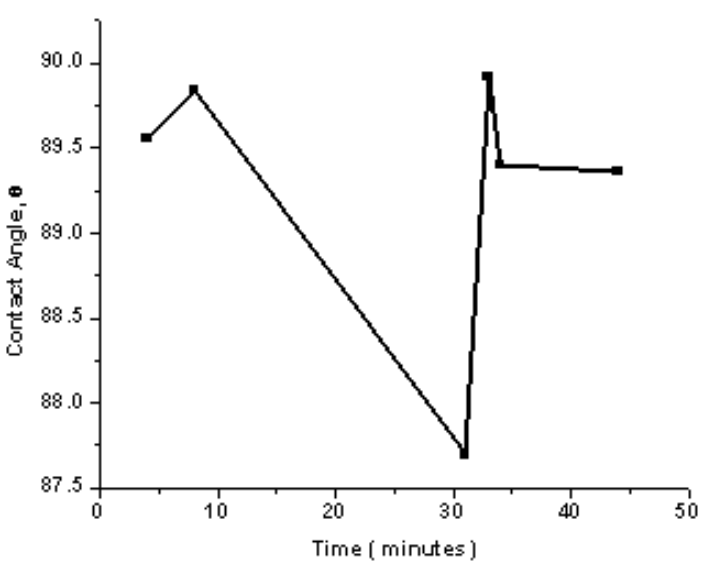

Figure 6. The Contact angle deduced for STSO modified kaolin from the experimental data according to Equation 2.

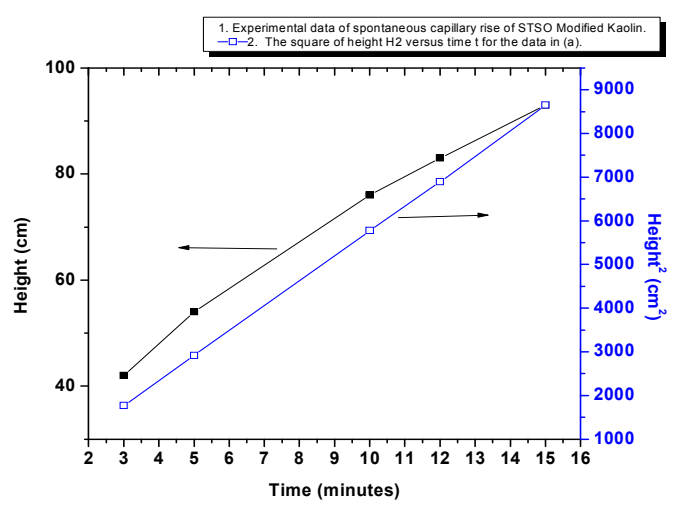

Figure 7. (a) Experimental data of spontaneous capillary rise of pristine kaolin. (b) The square of height $H^{2}$ versus time t for the data in

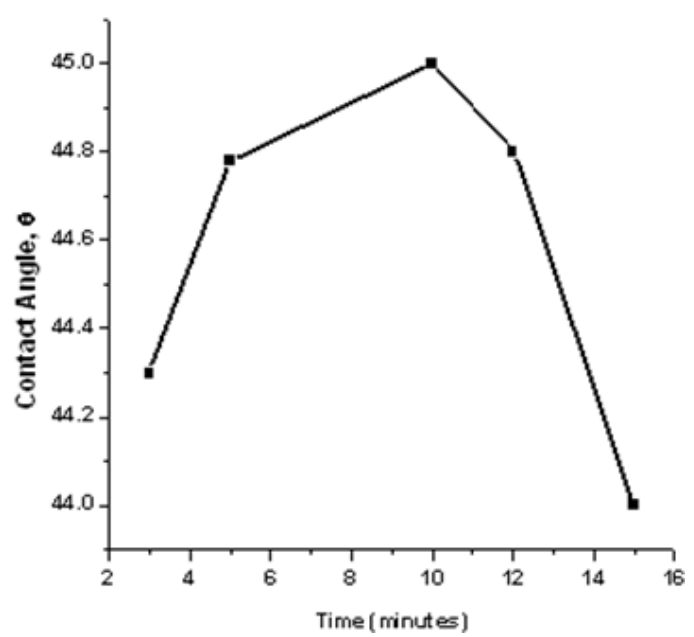

Figure 8. The contact angle deduced for unmodified kaolin from the experimental data according to Equation 2.

\section{Conclusion}

The following conclusions were drawn from this study:

1. The XRD analysis was performed to ascertain the effectiveness of the kaolin intercalation with the oleochemicals and change in the gallery distances of the modified clay. However, it was difficult to differentiate 
intercalation, exfoliation and delamination from the XRD result obtained. The XRD patterns of SRSO-modified and STSO-modified kaolins indicated that the kaolinite interlayer region has expanded along the c-axis as a result of the intercalation of the oleo derivatives achieved by employing hydrazine hydrate as co-intercalate.

2. The FTIR studies show the presence of organic modification at bands $1564 \mathrm{~cm}^{-1}$ and $1553 \mathrm{~cm}^{-1}$ for the SRSO and STSO modified kaolins, respectively.

3. The increase in the contact angles of the modified kaolins to $\sim 90^{\circ}$ from the value of $\sim 45^{\circ}$ obtained for the pristine kaolin indicates that there was surface modification of the kaolin from hydrophilic to hydrophobic.

\section{Acknowledgements}

The authors thank Dr. Suresh Das, Director, National Institute for Interdisciplinary Science and Technology, Thiruvananthapuram, Kerala, India for providing the facilities for the work; Centre for International Co-operation in Science for DST-RTFDCS Fellowship to C.O.M and Prof. Sam Omenyi of Department of Mechanical Engineering, NnamdiAzikiwe University, Awka, Nigeria for fruitful discussions.

\section{References}

[1] Bellotto, M., Gualtieri, A., and Artioli, G., 1995. Kinetic study of the kaolinite mullite reaction sequence. Part I: kaolinite dehydroxylation. PhysChem Miner., 22, 207-14.

[2] Cheng, H., Liu, Q, Yang, J., Ma, S., and Frost, R.L., 2012. The thermal behavior of kaolinite intercalation complex-A review: Part 1. ThermochimicaActa (in press) retrieved from http://dx.doi.org/10.1016/j.tca.2012.04.005.

[3] Ciullo, P.A., 1996. Industrial Minerals and Their Uses: A Handbook and Formulary. Noyes Publications, NJ, USA.

[4] Dai, J.C., Huang, J.T., 1999. Surface modification of clays and clay-rubber composites. Applied Clay Science, 15, $51-65$.

[5] Gualtieri, A., Bellotto, M., Artioli, G., 1995. Kinetic study of the kaolinite mullite reaction sequence. Part 2: mullite formation. PhysChem Miner., 22,215-22.

[6] Guessoum, M., Nekkaa, S., Fenouillot-Rimlinger, F., Haddoui, N., 2012. Effects of kaolin surface treatments on the thermomechanical properties and on the degradation of polypropylene. Internatl. J. Polym. Sci. http://dx.doi.org/10.1155/2012/549154.

[7] Hołownia, D., Kwiatkowska, I., Hupka, J., 2008. An investigation on wetting of porous materials. Physicochemical Problems of Mineral Processing, 42, 251-262.
[8] Krishnan, A.K., George, T.S., Anjana, R., Joseph, N., George, K.E., 2012. Effect of modified kaolin clays on the mechanical properties of polypropylene/polystyrene blends. J. Applied Polym. Sci., 127 (2), 1409-1415. http://dx.doi.org/10.1002/app.38043.

[9] Lucas, R. 1918.Ueber das Zeitgesetz des KapillarenAufstiegs von Flussigkeiten (in German) Kolloid Z., 23: 15

[10] Ma, X., Bruckard, W.J., 2010. The effect of $\mathrm{pH}$ and ionic strength on starch-kaolinite interactions. International. J. Mineral Process. 94, 111-114.

[11] Mgbemena, C.O., Ibekwe, N.O., Rugmini, S., Menon, A.R.R., 2013. Characterization of kaolin intercalates of oleochemicals derived from rubber seed (Heveabrasiliensis) and tea seed (Cameliasinensis) oils. Journal of King Saud University-Science,http://dx.doi.org/10.1016/j.jksus.2012.1 1.004 .

[12] Murray, H.H., 2007. Applied Clay Mineralogy: Occurrences, Processing and Application of Kaolins, Bentonites, Palygorskite-Sepiolite and Common Clays, First Edn. Elsevier, Amsterdam.

[13] Neumann, A. W., Good, R.J., 1979. Techniques of Measuring Contact Angles, Surface and Colloid Science, Volume II, Experimental Methods, Eds: R.J. Good and R. R. Stromberg, Plenum Press, New York.

[14] Preetha, N.K., Rani, J., 2012. Nanokaolin clay as reinforcing filler in nitrile rubber, Internatl. J. Sci. Engg. Res., 3, 3.

[15] Rugmini, S., Menon, A.R.R., 2008. Organomodified kaolin as a reinforcing filler for natural rubber, J. ApplPolymSc.i 107, 3476-3483.

[16] Songfang, Z., Shangchang, Q., Yuying, Z., Lei, C., Yong, G., 2011.Synthesis and characterization of kaolin with polystyrene via in-situ polymerization and their application in polypropylene, Materials and Design, 32, 957-963.

[17] Soriano, J., Mercier, A., Planet, R., Hernandez-Machado, A., Rodriguez, M.A., Ortin. J., 2005. Anomalous roughening of viscous fluid fronts in spontaneous imbibition, Phys. Rev. Lett. 95, 104501.

[18] Washburn, E. W., 1921. The dynamics of capillary flow. Phys. Rev., 17, 273-283.

[19] Xu, Z., Masliyah, J. H., 2002. Contact angle measurement on oxide and related surfaces, in: Encyclopedia of Surface and Colloid Science, Hubbard A. (Ed.), Marcel Dekker, New York, 1228-1241.

[20] Xue, H.T., Fang, Z.N., Yang, Y., Huang, J.P., Zhou, L.W., 2006. Contact angle determined by spontaneous dynamic capillary rises with hydrostatic effects: Experiment and Theory, Chem. Phy. Lett., 432, pp.326-330.

[21] Yahaya, L.E., Adebowale, K.O., Olu-Owolabi, B.I., Menon, A.R.R., Rugmini, S., Chameswary, J., 2010. Natural rubber/organoclay nanocomposites: Effect of filler dosage on the physico-mechanical properties of vulcanizates, African $J$. Pure Appl. Chem. 4 (4), 198-205. 